\title{
Predictive factors for difficult mask ventilation in the obese
}

\section{surgical population [version 1; peer review: 2 approved, 1}

\section{approved with reservations]}

\author{
Davide Cattano (iD) , Anastasia Katsiampoura², Ruggero M. Corso3, \\ Peter V. Killoran ${ }^{1}$, Chunyan Cai ${ }^{4}$, Carin A. Hagberg ${ }^{1}$ \\ ${ }^{1}$ Department of Anesthesiology, University of Texas Medical School at Houston, Houston, TX 77030, USA \\ 2Department of GI Medical Oncology, MD Anderson Cancer Center Hospital, Houston, TX 77030, USA \\ ${ }^{3}$ Emergency Department, Anesthesia and Intensive Care Section, GB Morgagni-L.Pierantoni Hospital, Forli, 47121, Italy \\ ${ }^{4}$ Division of Clinical and Translational Sciences, Department of Internal Medicine, The University of Texas Medical School at Houston, \\ Houston, TX 77030, USA
}

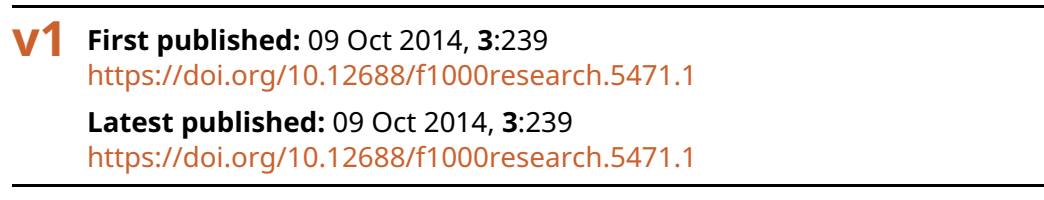

\section{Abstract}

\section{Background}

Difficult Mask Ventilation (DMV), is a situation in which it is impossible for an unassisted anesthesiologist to maintain oxygen saturation $>90 \%$ using $100 \%$ oxygen and positive pressure ventilation to prevent or reverse signs of inadequate ventilation during mask ventilation. The incidence varies from $0.08-15 \%$. Patient-related anatomical features are by far the most significant cause. We analyzed data from an obese surgical population (BMI> $30 \mathrm{~kg} / \mathrm{m}^{2}$ ) to identify specific risk and predictive factors for DMV.

\section{Methods}

Five hundred and fifty seven obese patients were identified from a database of 1399 cases associated with preoperative airway examinations where mask ventilation was attempted. Assessment of mask ventilation in this group was stratified by a severity score (0-3), and a step-wise selection method was used to identify independent predictors. The area under the curve of the receiver-operatingcharacteristic was then used to evaluate the model's predictive value. Adjusted odds ratios and their $95 \%$ confidence intervals were also calculated.

\section{Results}

DMV was observed in 80/557 (14\%) patients. Three independent predictive factors for DMV in obese patients were identified: age 49 years, short neck, and neck circumference $43 \mathrm{~cm}$. In the current study th sensitivity for one factor is 0.90 with a specificity 0.35 . However, the specificity increased to 0.80 with inclusion of more than one factor.

Conclusion

According to the current investigation, the three predictive factors are

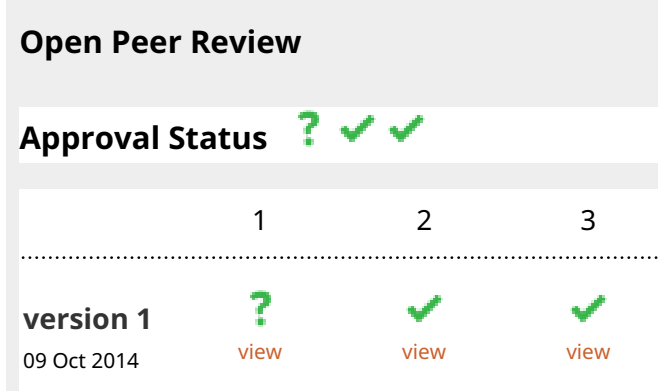

1. Basem Abdelmalak (D), Cleveland Clinic, Cleveland, USA

2. Peter Szmuk, University of Texas

Southwestern, Dallas, USA

3. Mirsad Dupanović, University of Kansas, Kansas City, USA

Any reports and responses or comments on the article can be found at the end of the article. 
strongly associated with DMV in obese patients. Each independent risk factor alone provides a good screening for DMV and two factors substantially improve specificity. Based on our analysis, we speculate that the absence of at least 2 of the factors we identified might have a significant negative predictive value and can reasonably exclude DMV, with a negative likelihood ratio 0.81 .

\section{Keywords}

Airway Management, Mask Ventilation, Obesity, Obstructive Sleep

Apnea

Corresponding author: Davide Cattano (Davide.Cattano@uth.tmc.edu)

Competing interests: No competing interests were disclosed.

Grant information: This study was sponsored by the Foundation in Anesthesia, Education and Research as the 2007 FAER Education Grant. Dr. Carin A. Hagberg was the Principle Investigator and Dr. Davide Cattano, the Co-Investigator

The funders had no role in study design, data collection and analysis, decision to publish, or preparation of the manuscript.

Copyright: ( 2014 Cattano D et al. This is an open access article distributed under the terms of the Creative Commons Attribution License, which permits unrestricted use, distribution, and reproduction in any medium, provided the original work is properly cited. Data associated with the article are available under the terms of the Creative Commons Zero "No rights reserved" data waiver (CC0 1.0 Public domain dedication).

How to cite this article: Cattano D, Katsiampoura A, Corso RM et al. Predictive factors for difficult mask ventilation in the obese surgical population [version 1; peer review: 2 approved, 1 approved with reservations] F1000Research 2014, 3:239 https://doi.org/10.12688/f1000research.5471.1

First published: 09 Oct 2014, 3:239 https://doi.org/10.12688/f1000research.5471.1 


\section{Introduction}

Bag mask ventilation commonly precedes the establishment of a secure airway by endotracheal intubation. However, the degree of difficulty encountered is variable ${ }^{1-4}$, with the incidence of Difficult Mask Ventilation (DMV) varying from $0.08-15 \%$ depending on the criteria used for the definition. The American Society of Anesthesiologists' (ASA) original definition recognized DMV as a situation where it is not possible for the unassisted anesthesiologist to maintain the oxygen saturation $>90 \%$ using $100 \%$ oxygen and positive pressure ventilation, or to prevent or reverse signs of inadequate ventilation ${ }^{5}$. Subsequently, many other definitions have evolved taking into account patient-independent factors that contribute to DMV, such as provider--and equipment-related factors ${ }^{5}$. Moreover, as an effort to overcome subjective definitions, several grading scales have been proposed, including Adnet's and Han's scales ${ }^{1,6}$.

In the face of DMV, critical hypoxemia may rapidly ensue and emphasizes the need for proper identification of risk factors during the preoperative assessment. Obese patients remain one of the most challenging patient populations for airway management ${ }^{7-9}$, with difficulties arising due to both anatomical features and functional changes ${ }^{10,11}$. Current protocols for preoperative evaluation focus not only on anatomic characteristics, but also on the identification of systemic features that are associated with airway obstruction and physiologic disarrangements, such as obstructive sleep apnea syndrome $(\mathrm{OSA})^{8,12}$. For instance, in the general surgical population, a history of OSA has been found to be an independent risk factor of impossible mask ventilation ${ }^{13,14}$, and patients with a high BMI have a high risk for $\mathrm{OSA}^{12}$. However, despite the known association between DMV, obesity, and OSA, there are no established predictive criteria, nor a simple scoring system which could predict DMV in the obese population.

In the present investigation, we primarily aimed to identify specific risk and predictive factors for difficult mask ventilation in obese patients and secondarily we attempted to correlate history and predicted factors related to OSA with DMV. We performed a retrospective analysis based on an existing database ${ }^{14}$.

\section{Methods}

A retrospective investigation was performed to identify predictive markers of DMV in obese patients at Memorial Hermann HospitalTexas Medical Center utilizing an existing database of airway assessment and airway management records ${ }^{4,14}: 1399$ anesthetics were identified where both mask ventilation was attempted and a pre procedure airway evaluation was documented. Of these, 557 obese patients were identified and included for analysis. The preoperative assessment utilized a dedicated airway assessment form ${ }^{14}$ which included Mallampati pharyngeal classification (modified by Samsoon and Young $)^{15}$, inter-incisor gap and thyromental distance $(\mathrm{cm})$ measured with the neck extended, sternomental distance, BMI, neck circumference $(\mathrm{cm})$ measured at the level of the thyroid cartilage, dentition status, presence of facial hair, facial or neck trauma, nasal deficiencies, neck mobility grade (which was divided into three categories according to the mouth-occiput distance), diagnosis of OSA according to patient history, perceived short neck, history of difficult intubation, and cervical spine abduction. Due to the retrospective nature of the study we were able to assess the OSA status only by the patient history. The degree of DMV classified by the provider performing the case by a severity score ${ }^{1}: 0=$ easy, $1=$ oral airway used, $2=$ two handed ventilation and $3=$ extraglottic device required. Based on the severity, mask ventilation was considered True DMV if the ease of mask ventilation was graded as 2 or 3 and False DMV if it was graded as 0 or 1 . During attempts at mask ventilation, all obese patients were placed in the head elevated laryngoscopy position and the operating room table was titled in the reverse Trendelenburg position. Vital signs were monitored according to ASA standard general anesthesia monitoring. Neuromuscular blocking agent utilization and/or the time of administration, dosage and reason for administration was not captured in the source database and therefore not included in this retrospective investigation.

\section{Statistical analysis}

Statistical analyses was performed using SAS 9.3 (SAS Institute, Cary, NC, USA). A p-value $<0.05$ was considered significant. Obese patients with or without DMV were compared. Values were reported as mean \pm standard deviation for continuous variables and frequency (percentage) for categorical variables for all preoperative patient characteristics. First, a univariate comparison between patients with or without DMV was performed using two sample t-test for continuous variables and Chi-square test or Fisher exact test, as appropriate, for categorical variables. Age was dichotemized based on a threshold of 49 years and neck circumference of $43(\mathrm{~cm})$, based on recognized risk threshold ${ }^{7}$. All variables with a p-value $<0.20$ in univariate analysis were entered into a multivariate logistic regression model. Stepwise selection method was used to identify independent predictors of DMV. All variables that were statistically significant with a $\mathrm{p}<0.05$ were established as independent predictors. Age and neck circumference were dichotomized according to clinical suggestions, using the optimal cut-off value identified by maximizing the sum of sensitivity and specificity for the primary outcome to obtain the best accuracy. In addition, the area under the curve of the receiver-operating-characteristic was calculated to evaluate the resulting model's predictive value. The adjusted odds ratios and their $95 \%$ confidence intervals were also calculated.

\section{Results}

A total of 557 cases of attempted mask ventilation were recorded in obese patients, as shown in Table 1, of which 78 were considered to be DMV (14.3\%). Patient characteristics and statistical correlations between DMV and preoperative variables are presented in Table 2.

Based on a univariate analysis, a total of 6 factors were identified with a $\mathrm{p}$ value $<0.05$ including: age, gender, neck circumference, absence of teeth, short neck (subjective) and OSA (suspected or diagnosed). Thresholds used were based on clinical suggestions.

Table 1. Summary statistics for MVEase.

\begin{tabular}{|l|l|}
\hline MVEase & $\begin{array}{l}\text { Frequency (percentage) } \\
\mathbf{N}=557\end{array}$ \\
\hline 0 & $267(47.9)$ \\
\hline 1 & $210(37.7)$ \\
\hline 2 & $77(13.8)$ \\
\hline 3 & $3(0.5)$ \\
\hline
\end{tabular}

Define DMV=True if MVEase $=2,3$ and DMV=False if MVEase $=0,1$ 
Age was dichotomized based on a threshold of 49 years of, and neck circumference based on, $43 \mathrm{~cm}$. Incorporation of these 6 factors into a multivariate logistic regression model identified 3 independent predictive factors for DMV in obese patients. The model used stepwise selection and identified age $\geq 49$ years, short neck, and neck circumference $\geq 43 \mathrm{~cm}$ (Table 3 ) as statistically significant. OSA, gender, and absence of teeth were not considered significant in the multivariate model.

Although a total of 3 risk factors were identified, no individual subject had more than 2 risk factors. The 3 independent risk factors identified were then applied to all cases where DMV was encountered

Table 2. Preoperative patient characteristics by DMV status.

\begin{tabular}{|c|c|c|c|}
\hline \multirow[b]{2}{*}{ Variables } & \multicolumn{2}{|c|}{ DMV } & \multirow[b]{2}{*}{$p$-value } \\
\hline & $\begin{array}{c}\text { False (MVEase }=0,1) \\
\qquad=477\end{array}$ & $\begin{array}{l}\text { True (MVEase }=2,3 \text { ) } \\
\qquad N=80\end{array}$ & \\
\hline $\begin{array}{l}\text { Age (year) } \\
\geq 49\end{array}$ & $\begin{array}{l}45.6 \pm 15.0 \\
197(41.3)\end{array}$ & $\begin{array}{l}48.4 \pm 13.2 \\
47(58.8)\end{array}$ & $\begin{array}{l}0.124 \\
0.004\end{array}$ \\
\hline Male & 206 (43.2) & $44(55.0)$ & 0.049 \\
\hline BMI $\left(\mathrm{kg} / \mathrm{m}^{2}\right)$ & $36.5 \pm 5.6$ & $37.7 \pm 6.1$ & 0.091 \\
\hline $\begin{array}{l}\text { NeckCirc } \\
\geq 43\end{array}$ & $\begin{array}{c}41.8 \pm 4.6 \\
213(44.7)\end{array}$ & $\begin{array}{l}44.4 \pm 4.5 \\
53(66.3)\end{array}$ & $\begin{array}{c}<0.0001 \\
0.0003\end{array}$ \\
\hline InterIncisors & $4.8 \pm 0.9$ & $4.8 \pm 0.9$ & 0.768 \\
\hline Thyromental & $7.9 \pm 1.7$ & $8.0 \pm 1.7$ & 0.724 \\
\hline Sternomental & $15.3 \pm 2.3$ & $15.2 \pm 2.0$ & 0.738 \\
\hline HxDiffIntub & $2(0.4)$ & $0(0)$ & NR \\
\hline $\begin{array}{l}\text { NeckMobGrade } \\
1 \\
2,3\end{array}$ & $\begin{array}{l}424(88.9) \\
53(11.1)\end{array}$ & $\begin{array}{l}65(81.3) \\
15(18.8)\end{array}$ & 0.053 \\
\hline $\begin{array}{l}\text { Mallampati } \\
\text { I, II } \\
\text { III, IV }\end{array}$ & $\begin{array}{l}382(80.1) \\
95(19.9)\end{array}$ & $\begin{array}{l}62(77.5) \\
18(22.5)\end{array}$ & 0.595 \\
\hline CSpineAbn & $14(2.9)$ & $5(6.3)$ & 0.172 \\
\hline NoTeeth & $29(6.1)$ & $10(12.5)$ & 0.037 \\
\hline FacHair & $43(9.0)$ & $12(15.0)$ & 0.097 \\
\hline FacTrauma & $4(0.8)$ & $0(0)$ & NR \\
\hline FullStomach & $3(0.6)$ & $1(1.3)$ & 0.543 \\
\hline NasalDef & $1(0.2)$ & $1(1.3)$ & 0.267 \\
\hline NeckTrauma & $3(0.6)$ & $2(2.5)$ & 0.153 \\
\hline ShortNeck & $53(11.1)$ & $21(26.3)$ & 0.0002 \\
\hline ObsSA & 108 (22.6) & 29 (36.3) & 0.009 \\
\hline $\begin{array}{l}\text { ResYear } \\
\text { CA-1, CA-1-2 } \\
\text { CA-2, CA-2-3, CA-3 }\end{array}$ & $\begin{array}{l}362(75.9) \\
115(24.1)\end{array}$ & $\begin{array}{l}60(75.0) \\
20(25.0)\end{array}$ & 0.863 \\
\hline
\end{tabular}

NR: not reported due to zero cells. Values are reported as mean \pm SD and frequency (percentage).

Table 3. Independent predictors of difficult mask ventilation by multivariate logistic regression model.

\begin{tabular}{|l|c|c|c|c|}
\hline Predictor & $\begin{array}{c}\boldsymbol{\beta} \\
\text { Coefficient }\end{array}$ & $\begin{array}{c}\text { Standard } \\
\text { Error }\end{array}$ & $\boldsymbol{P}$ value & $\begin{array}{c}\text { Adjusted odds ratio } \\
\text { (95\% Confidence } \\
\text { Interval) }\end{array}$ \\
\hline Age $\geq 49$ & 0.707 & 0.251 & 0.005 & $2.03(1.24,3.32)$ \\
\hline NeckCirc $\geq 43$ & 0.804 & 0.259 & 0.002 & $2.23(1.35,3.71)$ \\
\hline Short Neck & 0.975 & 0.302 & 0.034 & $2.65(1.47,4.79)$ \\
\hline
\end{tabular}


to evaluate a predictive model for DMV in obese patients. The sensitivity, specificity, likelihood ratios, and predictive values were progressively calculated for patients with different numbers of risk factors. The adjusted odds ratios were analyzed (Table 4).

A ROC curve (Figure 1) evaluating the sensitivity and specificity of preoperative independent risk factors for DMV for BMI $>30 \mathrm{~kg} / \mathrm{m}^{2}$ patients was calculated. The model's c-statistic score was 0.65 with $95 \%$ CI of 0.59 to 0.70 . The sensitivity for one factor is 0.90 with a specificity of 0.35 . However with more than one factor, the specificity increased to the level of 0.80 .

\section{Discussion}

We performed a retrospective analysis based on a database of airway assessment and airway management records collected at Memorial Hermann Hospital-Texas Medical Center, a tertiary care center. Our study focused in stratification and the identification of DMV predictive factors in a surgical population of obese patients, while recently we reported DMV in the general population ${ }^{4}$.

In our cohort, the incidence of DMV in obese patients was $14 \%$. These findings are consistent with previous reports by Leoni and
$\mathrm{Kheterpal}^{7,13}$. In their study, Leoni et al. reported that the incidence of DMV is significantly higher in obese patients compared to the general surgical population ${ }^{7}$. We also compared the incidence of DMV in the obese population to the general surgical population, confirming a frequency of $14 \%$ and $8.8^{4,9}$ respectively. The finding emphasizes the different risk stratification of DMV in the obese patients. Interestingly, in our obese surgical population OSA was as frequent as $24 \%$, while in other studies the prevalence of OSA among bariatric surgery patients reaches up to $70 \%$ and, in the general population, is approximately $20 \%{ }^{16-18}$.

In the present investigation, the statistical analysis identified 3 novel independent predictive markers for DMV in obese population: (a) age $\geq 49$ years, (b) neck circumference $\geq 43 \mathrm{~cm}$, and (c) perceived short neck. In the general population 7 risk factors were previously identified, of which OSA and BMI were two of them ${ }^{4}$ : interestingly the latter together with facial hair and history of difficult intubation were not present in the current model. This could be attributed to the reduction of the sample size, to the specific characteristic of obese patient (which are not necessarily at increased risk of difficult intubation $)^{19}$ or the effect of the stratification used which could mask the effect of BMI and OSA.

Table 4. Diagnostic value of the cut-off for number of risk factors in predicting a difficult mask ventilation.

\begin{tabular}{|c|c|c|c|c|c|c|}
\hline $\begin{array}{l}\text { Cut-off for } \\
\text { number of } \\
\text { risk factors }\end{array}$ & Sensitivity & Specificity & $\begin{array}{l}\text { Likelihood } \\
\text { ratio positive }\end{array}$ & $\begin{array}{l}\text { Likelihood } \\
\text { ratio negative }\end{array}$ & $\begin{array}{l}\text { Positive } \\
\text { predictive value }\end{array}$ & $\begin{array}{l}\text { Negative } \\
\text { predictive value }\end{array}$ \\
\hline 1 & 0.90 & 0.34 & 1.36 & 0.29 & 0.19 & 0.95 \\
\hline 2 & 0.35 & 0.80 & 1.75 & 0.81 & 0.23 & 0.88 \\
\hline
\end{tabular}

Likelihood ratio positive=Sensitivity/(1-Specificity) Likelihood ratio negative $=(1-$ Sensitivity $) /$ Specificity.

Table 4 displays the sensitivity and specificity if we use the given value of the number of risk factors possessed by patients as a cut-off to classify DMV. For example, when we use number of risk factors at 1 as a cut-off, i.e., any patients with $>=1$ risk factors will be classified as $\mathrm{DMV}=1$ and any patients with $<1$ risk factors will be classified as $\mathrm{DMV}=0$, the sensitivity will be 0.90 and specificity will be 0.34 . Cut-off at 1,2 are calculated and displayed.

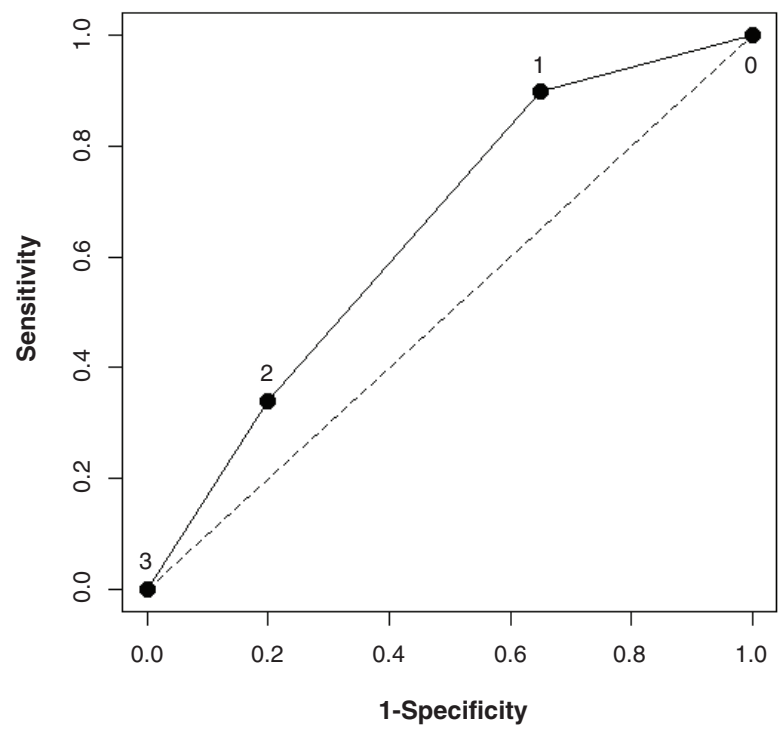

Figure 1. A receiver-operating-characteristic $(\mathrm{ROC})$ curve evaluating the sensitivity and specificity of preoperative independent risk factors for difficult mask ventilation for $\mathbf{B M I}>=\mathbf{3 0}$ patients. Three independent predictors for difficult mask ventilation were identified using logistic regression: age of $49 \mathrm{yr}$ or older, NeckCirc of 43 or greater, and Short Neck. The area under the curve was 0.65 (95\% confidence interval: $0.59-0.70)$. 
Based on our analysis, we speculate that the absence of at least 2 of the factors we identified might have a significant negative predictive value and can reasonably exclude DMV, with a negative likelihood ratio 0.81 . To our knowledge, this is the first time that short neck and age $\geq 49$ years are recognized as risk factors for DMV specifically in obese patients; however this is not totally unexpected. According to Langeron et al., age $>55$ years is correlated with DMV in the general population ${ }^{20}$, thus it seems reasonable that age would be a risk factor for DMV in the obese population as well. Shah et al. consider short and thick neck as an independent risk factor in the general population ${ }^{21}$. Neck circumference could be correlated to anatomical and physiological changes due to obesity that may increase the airway obstruction. Indeed the increased neck circumference is reflecting the presence of excessive palatal and pharyngeal soft tissue which intensifies the collapse of oropharynx during muscle relaxation. As a result increased neck circumference can make mask ventilation more difficult ${ }^{22,23}$.

Numerous prospective and retrospective clinical studies examined the correlation of patient-dependent and patient-independent characteristics, along with DMV, in the general surgical popula$\operatorname{tion}^{8,20,24}$, and led to the identification of several predictive factors for DMV. Specifically, Langeron et al. (as previously stated), Yildiz et al. and Kheterpal et al. demonstrated that increased BMI, history of snoring or OSA, as well as age $\geq 55$ years are risk factors for DMV in the general surgical population ${ }^{13,20,24}$. Additional factors in these studies included the presence of beard, Mallampati classification of III or IV, limited mandibular protrusion test, male gender, and airway masses or tumors. In our investigation, a total of 6 predictive markers of DMV were identified. However, Mallampati classification, limited mandibular protrusion and male sex did not reach significant correlation to DMV (step-wise analysis). All these findings are summarized in Table 5.

Last and with our surprise, OSA was not an independent risk factor for DMV in our cohort: this could be explained by the overlap of OSA predictive value with other factors, such as neck circumference, which has been shown to correlate with OSA ${ }^{25}$.

Few comments need to be reserved for the limitations of the present investigation. First, resident physicians were mostly involved in the study and we assumed that all anesthesiology residents had similar educational skills, based on our recent study ${ }^{9}$. Another limitation is the fact that the report regarding DMV is based on the subjective nature of the DMV definitions. Third, stepwise selection was sample dependent and may artificially enhance the performance of the model. Fourth, the retrospective nature of our data selection could contribute to bias in this study. Lastly, mask ventilation was assumed to be assessed as per current practice after induction and before muscle relaxation, yet the absence of an objective measure in the study about the status of paralysis and the use of muscle relaxant before or after the assessment of the mask ventilation could have partially affected the results.

\section{Conclusion}

In conclusion, in the present study we demonstrated that (a) age $\geq$ 49 years, (b) neck circumference $\geq 43 \mathrm{~cm}$, and (c) short neck (perceived) are strongly associated with DMV in obese patients. Thus, we suggest that these patient-dependent factors should be included in the pre-operative assessment to better predict DMV in the obese

Table 5. Independent predictors for DMV in general surgical population and obese patients.

\begin{tabular}{|c|c|c|c|c|}
\hline $\begin{array}{l}\text { Langeroon et al. (General } \\
\text { population) }\end{array}$ & $\begin{array}{l}\text { Khetepal et al. (General } \\
\text { population) }\end{array}$ & $\begin{array}{l}\text { Cattano et al. (General } \\
\text { population) }\end{array}$ & Leoni et al. (Obese) ${ }^{7}$ & Our model (Obese) \\
\hline \multirow[t]{2}{*}{$\begin{array}{l}\text { Age } \mathbf{5 5} \mathbf{~ y r} \\
2.26(1.34-3.81) \\
0.002\end{array}$} & $\begin{array}{l}\text { Male sex } \\
\text { 3. } 3(1.8-6.3) \\
0.001\end{array}$ & $\begin{array}{l}\text { Age } \geq \mathbf{4 7} \\
1.97(1.32-2.94) \\
0.001\end{array}$ & $\begin{array}{l}\text { Male gender } \\
1.55(0.97-2.46) \\
0.061\end{array}$ & $\begin{array}{l}\text { Age } \geq \mathbf{4 9} \\
2.03(1.24-3.32) \\
0.005\end{array}$ \\
\hline & $\begin{array}{l}\text { Neck radiation changes } \\
7.1(2.1-24.4) \\
0.002\end{array}$ & $\begin{array}{l}\text { Neck Circ } \geq \mathbf{4 0} \mathbf{~ c m} \\
2.54(1.59-4.05) \\
<0.001\end{array}$ & $\begin{array}{l}\text { Neck circumference } \\
1.17(1.08-1.27) \\
<0.0001\end{array}$ & $\begin{array}{l}\text { Neck Circ } \geq \mathbf{4 3} \mathbf{~ c m} \\
2.23(1.35-3.71) \\
0.002\end{array}$ \\
\hline $\begin{array}{l}\text { Lack of teeth } \\
2.28(1.26-4.10) \\
0.006\end{array}$ & $\begin{array}{l}\text { Mallampati III or IV } \\
2.0(1.1-3.4) \\
0.014\end{array}$ & $\begin{array}{l}\text { Hx Difficult intubation } \\
4.65(1.20-18.02) \\
0.026\end{array}$ & $\begin{array}{l}\text { Mallampati classification } \\
2.54(1.18-3.85) \\
0.009\end{array}$ & \\
\hline $\begin{array}{l}\text { History of snoring } \\
1.84(1.09-3.10) \\
0.02\end{array}$ & $\begin{array}{l}\text { Sleep apnea } \\
2.4(1.3-4.3) \\
0.005\end{array}$ & $\begin{array}{l}\text { OSA } \\
1.65(1.07-2.56) \\
0.023\end{array}$ & $\begin{array}{l}\text { Limited jaw protrusion } \\
1.98(1.03-4.28) \\
0.046\end{array}$ & \\
\hline $\begin{array}{l}\text { Presence of beard } \\
3.18(1.39-7.27) \\
0.006\end{array}$ & $\begin{array}{l}\text { Presence of beard } \\
1.9(1.1-3.3) \\
0.024\end{array}$ & $\begin{array}{l}\text { Facial Hair } \\
2.34(1.43-3.83) \\
<0.001\end{array}$ & & \\
\hline \multirow{2}{*}{ 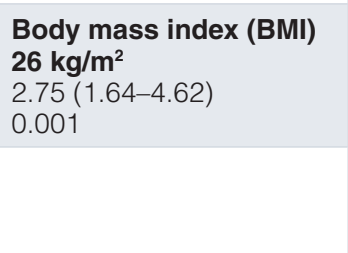 } & & $\begin{array}{l}\mathbf{B M I} \geq \mathbf{3 5} \mathbf{~ k g} / \mathbf{m}^{2} \\
2.09(1.35-3.23) \\
0.001\end{array}$ & & \\
\hline & & $\begin{array}{l}\text { Short Neck } \\
1.88(1.06-3.32) \\
0.023\end{array}$ & & $\begin{array}{l}\text { Short Neck } \\
2.65(1.47-4.79) \\
0.034\end{array}$ \\
\hline
\end{tabular}

Adjusted odds ratios with 95\% Confidence intervals and $\mathrm{P}$ values are noted respectively. 
population. Each one used singularly may provide an efficacious screening tool, while the association of 2 of them may be used to improve specificity. Since the prevalence of obese patients in the surgical population is increasing exponentially, further investigation is warranted that may elucidate the association of (1) patient-derived anatomical and functional characteristics, (2) physician-derived characteristics and (3) equipment characteristics with DMV in obese patient.

\section{Data availability}

Data have been obtained from databases at the Memorial Hermann Hospital, Texas Medical Center, Houston, IRB approval HSCMS-07-0144. The author can support applications to the Institutional Board to make the data accessible upon individual request. Please forward your requests to Davide Cattano.

\section{Author contributions}

Davide Cattano: study design, study monitoring, data analysis, data interpretation, manuscript preparation
Anastasia D. Katsiampoura: manuscript preparation, data analysis, data interpretation

Ruggero M. Corso: data interpretation, manuscript preparation

Peter V. Killoran: study monitoring, data collection, data analysis, data interpretation

Chunyan Cai: data analysis, manuscript preparation

Carin A. Hagberg: study design, study monitoring, manuscript preparation

\section{Competing interests}

No competing interests were disclosed.

\section{Grant information}

This study was sponsored by the Foundation in Anesthesia, Education and Research as the 2007 FAER Education Grant. Dr. Carin A. Hagberg was the Principle Investigator and Dr. Davide Cattano, the Co-Investigator.

The funders had no role in study design, data collection and analysis, decision to publish, or preparation of the manuscript.
1. Han R, Tremper KK, Kheterpal S, et al:: Grading scale for mask ventilation. Anesthesiology. 2004; 101(1): 267. PubMed Abstract | Publisher Full Text

2. Kheterpal S, Han R, Tremper KK, et al.: Incidence and predictors of difficult and impossible mask ventilation. Anesthesiology. 2006; 105(5): 885-91. PubMed Abstract | Publisher Full Text

3. Benumof JL: Management of the difficult adult airway. With special emphasis on awake tracheal intubation. Anesthesiology. 1991; 75(6): 1087-110. PubMed Abstract | Publisher Full Text

4. Cattano D, Killoran PV, Cai C, et al:: Difficult mask ventilation in general surgical population: observation of risk factors and predictors. [v1; ref status: approved1, http://f1000r.es/47z]. F1000Research. 2014; 3: 204. Publisher Full Text

5. Practice guidelines for management of the difficult airway. A report by the American Society of Anesthesiologists Task Force on Management of the Difficult Airway. Anesthesiology. 1993; 78(3): 597-602.

PubMed Abstract | Publisher Full Text

6. Adnet F: Difficult mask ventilation: an underestimated aspect of the problem of the difficult airway? Anesthesiology. 2000; 92(5): 1217-8. PubMed Abstract | Publisher Full Text

7. Leoni A, Arlati S, Ghisi D, et al.: Difficult mask ventilation in obese patients: analysis of predictive factors. Minerva Anestesiol. 2014; 80(2): 149-57. PubMed Abstract

8. Kheterpal S, Martin L, Shanks AM, et al.: Prediction and outcomes of impossible mask ventilation: a review of 50,000 anesthetics. Anesthesiology. 2009; 110(4): mask vent $891-7$.

PubMed Abstract | Publisher Full Text

9. Cattano D, Killoran PV, lannucci D, et al:: Anticipation of the difficult airway: preoperative airway assessment, an educational and quality improvement tool. Br J Anaesth. 2013; 111(2): 276-85 PubMed Abstract | Publisher Full Text | Free Full Text

10. Jense HG, Dubin SA, Silverstein PI, et al.: Effect of obesity on safe duration of apnea in anesthetized humans. Anesth Analg. 1991; 72(1): 89-93. PubMed Abstract | Publisher Full Text

11. Benumof JL: Obesity, sleep apnea, the airway and anesthesia. Curr Opin Anaesthesiol. 2004; 17(1): 21-30. PubMed Abstract | Publisher Full Text

12. Corso RM, Petrini F, Buccioli M, et al:: Clinical utility of preoperative screening with STOP-Bang questionnaire in elective surgery. Minerva Anestesiol. 2013; 80(8): 877-84. PubMed Abstract

13. Kheterpal S, Healy D, Aziz MF, et al:: Incidence, predictors, and outcome of difficult mask ventilation combined with difficult laryngoscopy: a report from the multicenter perioperative outcomes group. Anesthesiology. 2013; 119(6):
$1360-9$

PubMed Abstract | Publisher Full Text

14. Killoran PV, Maddukuri V, Altamirano A, et al:: Use of a comprehensive airway assessment form to predict difficult mask ventilation. Anesthesiology. 2011; A442.

Reference Source

15. Samsoon GL, Young JR: Difficult tracheal intubation: a retrospective study. Anaesthesia. 1987; 42(5): 487-90.

PubMed Abstract | Publisher Full Text

16. Lopez PP, Stefan B, Schulman Cl, et al.: Prevalence of sleep apnea in morbidly obese patients who presented for weight loss surgery evaluation: more evidence for routine screening for obstructive sleep apnea before weight loss surgery. Am Surg. 2008; 74(9): 834-8. PubMed Abstract

17. Lee W, Nagubadi S, Kryger MH, et al.: Epidemiology of Obstructive Sleep Apnea: a Population-based Perspective. Expert Rev Respir Med. 2008; 2(3): 349-64. PubMed Abstract | Publisher Full Text | Free Full Text

18. Gami AS, Caples SM, Somers VK: Obesity and obstructive sleep apnea. Endocrinol Metab Clin North Am. 2003; 32(4): 869-94. PubMed Abstract | Publisher Full Text

19. Brodsky JB, Lemmens HJ, Brock-Utne JG, et al:: Morbid obesity and tracheal intubation. Anesth Analg. 2002; 94(3): 732-6. PubMed Abstract | Publisher Full Text

20. Langeron $\mathrm{O}$, Masso $\mathrm{E}$, Huraux $\mathrm{C}$, et al.: Prediction of difficult mask ventilation. Anesthesiology. 2000; 92(5): 1229-36. PubMed Abstract | Publisher Full Text

21. Shah PN, Sundaram V: Incidence and predictors of difficult mask ventilation and intubation. J Anaesthesiol Clin Pharmacol. 2012; 28(4): 451-5. PubMed Abstract | Publisher Full Text | Free Full Text

22. Watanabe $\mathrm{T}$, Isono $\mathrm{S}$, Tanaka $\mathrm{A}$, et al:: Contribution of body habitus and craniofacial characteristics to segmental closing pressures of the passive pharynx in patients with sleep-disordered breathing. Am J Respir Crit Care Med. 2002; 165(2): 260-5. PubMed Abstract | Publisher Full Text

23. Isono S: Obstructive sleep apnea of obese adults: pathophysiology and perioperative airway management. Anesthesiology. 2009; 110(4): 908-21. PubMed Abstract | Publisher Full Text

24. Yildiz TS, Solak M, Toker K: The incidence and risk factors of difficult mask ventilation. J Anesth. 2005; 19(1): 7-11. PubMed Abstract | Publisher Full Text

25. Hiremath AS, Hillman DR, James AL, et al.: Relationship between difficult tracheal intubation and obstructive sleep apnoea. Br J Anaesth. 1998; 80(5): 606-11.

PubMed Abstract | Publisher Full Text 


\section{Open Peer Review}

\section{Current Peer Review Status:}

\section{Version 1}

Reviewer Report 07 November 2014

https://doi.org/10.5256/f1000research.5841.r6375

C 2014 Dupanović M. This is an open access peer review report distributed under the terms of the Creative Commons Attribution License, which permits unrestricted use, distribution, and reproduction in any medium, provided the original work is properly cited.

\section{Mirsad Dupanović}

Department of Anesthesiology, University of Kansas, Kansas City, KS, USA

I would like to compliment Dr. Cattano and his colleagues for undertaking the investigation on this important topic. Their results confirmed most of the risk factors that other investigators have also found may make mask ventilation difficult (studies cited in the reference section of this manuscript). However, Cattano et al. have attempted to go a step further and identify as to how many risk factors need to be present for mask ventilation to be difficult. They had a partial success in that venture. The definition of difficult mask ventilation in this study seems very reasonable and I hope it gets wide acceptance among those that manage airway.

I agree with Dr. Doyle's comment that it needs to be re-emphasized that this was a retrospective study and these results should be re-tested in a well designed prospective study.

Competing Interests: No competing interests were disclosed.

\section{I confirm that I have read this submission and believe that I have an appropriate level of expertise to confirm that it is of an acceptable scientific standard.}

Reviewer Report 05 November 2014

https://doi.org/10.5256/f1000research.5841.r6376

(C) 2014 Szmuk P. This is an open access peer review report distributed under the terms of the Creative Commons Attribution License, which permits unrestricted use, distribution, and reproduction in any medium, provided the original work is properly cited.

\section{Peter Szmuk}

Department of Anesthesiology and Pain Management, University of Texas Southwestern, Dallas, TX, USA 
Thank you for the opportunity to review this manuscript and my apologies for the long response time.

This manuscript comes from one of the world leading research centers on difficult airway and deals with a very important and possible life saving topic: the difficult mask ventilation (DMV). Based on a retrospective analysis the authors found that three factors (age $>49$, neck circumference $>43$ and short neck) are strong predictors for DMV in obese patients and thus, should be included in a pre-operative assessment. Despite the retrospective nature of the study, this screening tool should make an important contribution to the predictability of DMV especially in the obese patients. I would encourage the authors to expand their work into a prospective study.

\section{Minor comments:}

Methods section:

1399 anesthetics were identified to have both mask ventilation and airway evaluation. Please specify over what period and/or how many patients.

Please define "obese" patients and clarify the term "nasal deficiencies".

I am surprised that the dentition status was not one of the factors involved in the DMV. Is that due to the fact that very few patients in your group are edentulous? This might be different in other geographical areas. Could you comment on that?

Ethnicity and body fat distribution would be another factor to consider in a future study. Obese patients with predominant abdominal fat distribution might have normal neck and airway as compared to those with an equally distributed fat habitus.

Finally, one of the study limitations noted in the discussion section mentioned the skills level of the residents participating in these cases. This is a valid concern but I would also be interested to see if other factors related to the provider might play a role in DMV. From my clinical observation I noticed that providers with small hands have more difficulty with mask ventilation of a large, obese patient. I wander if anybody looked into this association.

Competing Interests: No competing interests were disclosed.

\section{I confirm that I have read this submission and believe that I have an appropriate level of expertise to confirm that it is of an acceptable scientific standard.}

Author Response ( ) 05 Nov 2014

Davide Cattano, University of Texas Medical School at Houston, Houston, USA

We acknowledge Dr Szmuk comments, and the discussion resulting could further strengthen the data reported. The study was undergone over a period of 18 months, and a selected review of all records with pre- and post intervention data available constituted the cohort analysis. The definition of obesity is the WHO, BMI greater and equal of $30\left(\mathrm{~kg} / \mathrm{m}^{2}\right)$. We recognize the limitations of a retrospective review and the deficiency in some of the 
definition, which are clinical indicators though in real world airway management. Indeed in a previous investigation we commented on the inevitable fact that certain predictors remains subjective and dependent on operator assessment. It is interesting that many classification based on standardized definition performs at most with $65 \%$ reliability. We agree with Dr Szmuk that body fat distribution is indeed perceived as an important factor. It is interesting that in other studies BMI as low as 26 were found to be associated (general population) and that in European and Asia based study the incidence of DMV would be variable based on other anatomical markers and different body weight, maybe confirming Dr Szmuk's observation.

Competing Interests: No competing interests were disclosed.

Reviewer Report 31 October 2014

https://doi.org/10.5256/f1000research.5841.r6608

(c) 2014 Abdelmalak B. This is an open access peer review report distributed under the terms of the Creative Commons Attribution License, which permits unrestricted use, distribution, and reproduction in any medium, provided the original work is properly cited.

\section{Basem Abdelmalak}

Department of General Anesthesiology, Cleveland Clinic, Cleveland, OH, USA

Thank you for the opportunity to review this very interesting manuscript that focuses on studying difficult mask ventilation in obese patients. This manuscript highlights an important safety consideration when caring for this patient population. The authors have appropriately discussed the limitations of this study. Of those, the most important is the retrospective nature of the study. Another limitation to consider is the lack of data on the use of muscle relaxants: how much and its timing relative to the assessment of the ventilation difficulty, etc. As one might imagine, there may have been variability related to the ongoing controversy of the administration of muscle relaxants either immediately after induction, or a bit delayed till confirmation of the ability to mask ventilate.

As we acknowledge such limitations and thus their impact on the validity of these results, we should keep in mind that the resulting increased awareness of these predictors will likely increase the likelihood of a thorough airway exam and making the right decision in managing such airways. As per the most recent ASA difficult airway algorithm (2013) a thorough airway evaluation will aid in deciding the safest pathway taken inclusive of the following factors: invasive vs, noninvasive, awake vs. asleep, videolaryngoscopy as first approach vs. DL, and finally maintaining spontaneous ventilation vs. muscle relaxation.

Competing Interests: No competing interests were disclosed.

I confirm that I have read this submission and believe that I have an appropriate level of
expertise to confirm that it is of an acceptable scientific standard, however I have 


\section{significant reservations, as outlined above.}

Author Response ( ) 31 Oct 2014

Davide Cattano, University of Texas Medical School at Houston, Houston, USA

Dr Abdelmalak comments are very appreciated, particularly considering his airway management expertise. The points underlined are significant to strenght discussion about our findings. We would like to comment about the muscle relaxation utilization: as clinical standard at our institution, muscle relaxant administration, the majority of the times, follows bag mask ventilatilability confirmation, but it is also true that several anesthesiologists actually utilize a different pattern (which it has been predicated by expert society as well).

Another important point pertains the predictors. It is interesting to map the risk predictors as per different studies have identified, and knowing the clinical practice pressure we are exposed to, making an effort for the few that seems to have a significant impact may be worth more than being distracted by others.

The last point is related to airway devices and techniques. As standard or routine utilization of certain devices becomes more common, the difficulty of airway management is also evolving. We cannot disregard in this sense the work of Caldiroli and Cortellazzi for instance on the utilization of Glidescope as primary laryngoscopy device: such usage has prompted a revisitation of the El-Ganzouri score, highlighting newer usage of predictive factors because of modification of airway difficulty and outcomes.

Lastly, It is reassuring that several investigations, which ours is one, particularly in different patient populations, are confirming in parallel same findings.

Competing Interests: No competing interests were disclosed.

The benefits of publishing with F1000Research:

- Your article is published within days, with no editorial bias

- You can publish traditional articles, null/negative results, case reports, data notes and more

- The peer review process is transparent and collaborative

- Your article is indexed in PubMed after passing peer review

- Dedicated customer support at every stage

For pre-submission enquiries, contact research@f1000.com 